\title{
Introduction of pneumococcal vaccine in national immunisation schedule in India: boon or bane?
}

\author{
Nayak R. ${ }^{1 *}$, Kumar Singh A. ${ }^{2}$, Pragyan Parida S. ${ }^{3}$, Padhy S. ${ }^{4}$, Guru Mishra K. \\ DOI: https://doi.org/10.17511/ijphr.2019.i6.05 \\ 1* Ranjeeta Nayak, Senior Resident, Department of Community Medicine and Family Medicine, All India Institute of Medical Sciences, \\ Bhubaneswar, Odisha, India. \\ 2 Arvind Kumar Singh, Assistant Professor, Department of Community Medicine and Family Medicine, All India Institute of Medical Sciences, \\ Bhubaneswar, Odisha, India. \\ 3 Swayam Pragyan Parida, Associate Professor, Department of Community Medicine and Family Medicine, All India Institute of Medical \\ Sciences, Bhubaneswar, Odisha, India. \\ ${ }^{4}$ Sarmistha Padhy, Assistant Professor, Department of Community Medicine, MKCG Medical College, Berhampur, Odisha, India. \\ 5 Kumar Guru Mishra, Junior Resident, Department of Community Medicine and Family Medicine, All India Institute of Medical Sciences, \\ Bhubaneswar, Odisha, India.
}

Vaccination is undoubtedly one of the most cost-effective child survival public health measure which are more affordable and accessible to community in preventing diseases. Government of India has undertaken several initiatives to strengthen maternal and child health services in the country and child immunisation being an important part of child healthcare system in India. In recent years, there has been introduction of various newer vaccines. Introduction of pneumococcal vaccine in selected states in year 2017 and plan to scale up in the entire country is the newest change in National Immunization Schedule. This review aims to identify various articles related to pneumococcal infection and vaccine highlighting the burden, serotypic distribution, available vaccines, evidence regarding vaccine safety, efficacy, acceptability and cost effectiveness, in order to provide sufficient understanding on the demand and need of this vaccine in India. Important factors underpinned by this article are though there is a need of vaccination due to severe form of pneumococcal infections and antibiotic resistance due to which many developed countries have included PCV in their regular immunisation programmes, however studies regarding effectiveness of pneumococcal vaccines in developing countries like India, data regarding the burden of pneumococcal infections are not available.

Keywords: Pneumococcal vaccine, Childhood survival, Vaccination

\section{Corresponding Author}

Ranjeeta Nayak, Senior Resident, Department of Community Medicine and Family Medicine, All India Institute of Medical Sciences, Bhubaneswar, Odisha, India.

Email: ranjeeta.nayak1310@gmail.com

\section{How to Cite this Article}

Nayak R, Singh AK, Parida SP, Padhy S, Mishra KG. Introduction of pneumococcal vaccine in national immunisation schedule in India: boon or bane? Public Health Rev Int J Public Health Res. $2020 ; 6(6): 239-245$.

Available From

https://publichealth.medresearch.in/index.php/ijphr/ article/view/122

$\begin{array}{cc}\begin{array}{c}\text { Manuscript Received } \\ 2019-10-30\end{array} & \begin{array}{c}\text { Review Round } \mathbf{1} \\ 2019-11-10\end{array} \\ \text { Conflict of Interest } \\ \text { No } & \text { Funding } \\ \text { Nil }\end{array}$

Review Round 2
2019-11-16
$\begin{gathered}\text { Ethical Approval } \\ \text { Yes }\end{gathered}$

Review Round 3

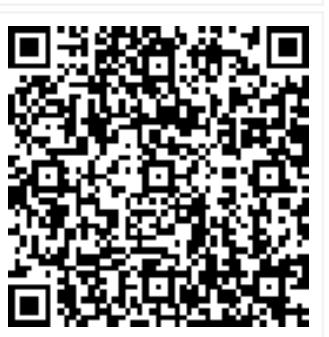

(C) 2020 by Ranjeeta Nayak, Arvind Kumar Singh, Swayam Pragyan Parida, Sarmistha Padhy, Kumar Guru Mishra and Published by Siddharth Health Research and Social Welfare Society. This is an Open Access article licensed under a Creative Commons Attribution 4.0 International License https://creativecommons.org/licenses/by/4.0/ unported [CC BY 4.0] 


\section{Introduction}

Vaccination is undoubtedly one of the most costeffective child survival public health measure. Eradication of small pox underpins immense potential of immunization as a public health measure. Also, vaccine sare more affordable and accessible to community in preventing diseases in comparison to therapeutic interventions [1].

History of Immunisation programme in IndiaThe Government of India has undertaken several initiatives to strengthen maternal and child health services in the country. Child immunisation is an important part of child health care system in India. The National Immunization Programme has taken many initiatives since its inception as Expanded Programme on Immunization in 1978.

The rate of acceleration of Immunization coverage was sluggish in previous decade with only 8 percentage point increase between 1992-93 and 2005-2006 from $35.4 \%$ to $43.5 \%$. As per NFHS-4, immunisation coverage has now increased to $62 \%$ in 2015-16 [2]. However, India's target for immunisation consists of an annual cohort of 26 million infants of which 38 percent does not receive all due vaccines. Moreover, there is also a large inter-state variation in the coverage of Routine Immunisation $[3,4]$.

Government of India has also implemented intensive campaigns to further boost the immunization coverage through Mission Indra Dhanush (2014) and Intensified Mission Indhra Dhanush. In recent years, there has been introduction of various newer vaccines such as second dose of measles, inactivated polio vaccine, and rota virus vaccine. Introduction of pneumococcal vaccine in selected states in year 2017 and plan to scale up in the entire country is the newest change in National Immunization Schedule (NIS) (Table 1).

This rapid expansion of immunization programme with introduction of newer vaccine needs to be evaluated carefully in a health system's perspective. From a public health point of view, factors that should be considered prior to introduction of a new vaccine are disease burden, safety and efficacy of candidate vaccine, affordability, acceptability and availability of the vaccine in a sustainable manner (i.e. production capacity), capacity of programme to bear the extra load, and lastly the cost effectiveness of the programme.
Here, we have discussed these factors in context of introduction of pneumococcal vaccine in NIS in India.

Table No-1: History of Immunisation Program in India [3].

\begin{tabular}{|l|l|}
\hline \multicolumn{1}{|c|}{ Expanded Program on Immunisation launched } & \multicolumn{1}{c|}{1978} \\
\hline Universal Immunization Program (UIP) & 1985 \\
\hline Introduction of measles vaccine & 1990 \\
\hline Hepatitis B introduced & $2002-03$ \\
\hline UIP came under NRHM & 2005 \\
\hline Introduction of second dose of measles & 2010 \\
\hline Japanese Encephalitis vaccines introduced & 2011 \\
\hline National Vaccine Policy & 2011 \\
\hline Introduction of Pentavalent vaccine & 2011 \\
\hline IPV introduced & 2015 \\
\hline Introduction of Rotavirus vaccine & 2016 \\
\hline Introduction of Pneumococcal vaccine & 2017 \\
\hline
\end{tabular}

\section{Method and Results}

An update review (Non-systematic review) was conducted to identify various articles related pneumococcal infection and Pneumococcal Vaccine. Relevant articles were selected forth is review that were published in Pub Med between 1990 to 2017 highlighting the burden and serotypic distribution of pneumococcal disease, available vaccines, evidence regarding vaccine safety, efficacy, acceptability and cost effectiveness.

Additionally, information were also extracted from published fact sheets and guidelines available to provide sufficient understanding in this context.

\section{Discussions}

\section{Burden of Pneumococcal Diseases in children}

Global: Pneumonia is the single largest infectious cause of death in children worldwide. Globally $6 \%$ ofneonataldeaths, 23\%ofpostneonataland15\% ofunder-fivedeaths are due to acute respiratory infections. In 2015, Pneumonia killed 0.9 million children under the age of 5 and most of its victims were less than two years [5].

Incidence of Community Acquired Pneumonia in children under 5 years of age is 0.27 episodes per child-year in African region, followed by 0.26 in South East Asian region, 0.23 in Eastern Mediterranean region, 0.11 in Western Pacific region, 0.08 in American region, and 0.03 in European region [6]. 




Fig- 1: Global causes of child deaths [7].

Burden of pneumococcal pneumonia in children: Pneumonia can be caused by a number of infectious agents, including viruses, bacteria, or fungi [8]. The most common bacterial causes are streptococcus pneumonia followed by Haemophilus influenza. Respiratory syncytial virus is most common cause of viral pneumonia [8].

Streptococcus Pneumonia (Pneumococcus) causes both severe and non-severe diseases. It is a leading cause of bacterial pneumonia, meningitis, and sepsis in children worldwide. Otitis media, sinusitis and bronchitis are more common, but less serious manifestations of this infection [9]. In developing countries, deaths from pneumococcal disease are common in children under 5 years.

Many countries lack national estimates of exact burden of diseases caused by pneumococcus. However, the disease rates and mortality are higher in developing than in industrialized settings, with the majority of deaths occurring in Africa and Asia [8].

India: In India $5 \%$ of neonatal deaths, $28 \%$ of post-neonatal and $15 \%$ of under-five deaths are due to acute respiratory infections [5]. The pneumonia working group of Child Health Epidemiology Reference Group (CHERG) had estimated in 2004 , incidence of 0.37 episodes per child year for clinical pneumonia among children $<5$ years in India [10].

As per CHERG, in 2010, pneumonia was responsible for 0.397 million deaths of total estimated 1.682 million under-5 deaths in India [11]. Jaiswal $\mathrm{N}$ et al in a systematic review showed that S. Pneumonia in India causes $10.58 \%$ of invasive diseases, $7.62 \%$ of severe pneumonia cases, and $11.21 \%$ of meningitis cases in children with suspected bacterial diseases aged 1 month to 12 years [12].
According to Yadav KK et al (systematic review), in India, annually, 0.35-0.37 million deaths in children occur under 5 years of age due to Community Acquired Pneumonia (CAP), which is around 13-16\% of total annual mortality in this age group. Among the Indian states, Uttar Pradesh has the maximum number of CAP cases and deaths (24\% cases, $26 \%$ deaths) in children under 5 years of age followed by Bihar ( $16 \%$ cases, $22 \%$ deaths), Madhya Pradesh ( $9 \%$ cases, $12 \%$ deaths) and Rajasthan ( $8 \%$ cases, $11 \%$ deaths).

The case fatality rate (CFR) due to CAP in children under 5 years of age ranged from $2.5 \%$ to $11.8 \%$.S. pneumoniae was most common organism (30$50 \%)$; followed by $\mathrm{H}$. influenzae type b ( $8.8 \%)$ and Staphylococcus aureus ( 7-23\%) [6]. However, there is no nationally representative study of any Pneumococcal Disease incidence from the community to reflect actual burden of the disease. The incidence of invasive pneumococcal disease (IPD) in India is difficult to estimate due to the large population and geographic size and the absence of a national surveillance system for IPD.

\section{Serotypic Distribution of pneumococcal pneumonia}

Global: Pneumococcus is classified into a number of serotypes, based on the composition of its outer capsule. There are more than 90 known serotypes whose prevalence varies by age, geographic region, disease spectrum, disease severity and overtime. A wide variety of serotypes cause non-invasive diseases such as otitis media and sinusitis, serotypes1, 5, 6A, 6B, 14, 19F, and 23F are common causes of invasive pneumococcal disease (IPD) globally in children < 5 years of age. Serotypes $23 \mathrm{~F}$ and $19 \mathrm{~F}$ are responsible for $9 \%-18 \%$ of cases globally. Serotypes 1,5 , and 14 to get account for $28 \%-43 \%$ of IPD across regions and for about $30 \%$ of IPD in 20 of the world's poorest countries. Serotype $18 \mathrm{C}$ is common in high-income countries (i.e., Europe, North America). Some serotypes such as 6B, 9V, 14, 19A, 19F, and 23F are more likely than others to be associated with drug resistance $[12,13]$.

India: The data on serotypic distribution of pneumococcal pneumonia in the country is sparse and limited to a few hospitals based studies. Based on two studies by Alliance for surveillance of invasive pneumococci (ASIP) by M/s GSK and Invasive Bacterial Infection Surveillance (IBIS), the most prevalent serotypes in India are $6 \mathrm{~A}, 6 \mathrm{~B}, 1$, 
19F, 19A, 14, 5, 7, 9V, 33 and 17. Asper IBIS Serotypes 1 and 5 accounted for $29 \%$ of disease [14]. However, IBIS study was entirely hospital based and studied invasive pneumococcal infections. ASIP showed serotypes $14(16 \%), 5(14.6 \%), 1$ $(11.1 \%), 19 \mathrm{~F}(9.7 \%)$ and $6 \mathrm{~B}(6.7 \%)$ were most frequent serotypes [15]. This study do not consider the whole country as major part of central India was not represented. In a systematic review by Jaiswal $\mathrm{N}$ et al, serotype 14 was found to be the most common serotype followed by $5,1,19 \mathrm{~F}$, and $6 \mathrm{~B}$ [12]. As per Yadav KK et al, serotypes 1 and 5 were found to be most prevalent followed by $4,6 \mathrm{~A}$ and $6 \mathrm{~B}, 7,12,14,15,19 \mathrm{~F}, 23$, and 45 [6]. Data regarding change in the serotype prevalence overtime are lacking.

\section{Different types of Pneumococcal Vaccines [16]}

Types and Composition: Pneumococcal vaccines are two types: Pneumococcal Polysaccharide vaccine (PPsV) and Pneumococcal conjugate vaccines (PCV). PPsV is purified free polysaccharide derived from surface capsule of bacterium which is poor antigenic. PCV is resulted after conjugation of the capsular polysaccharide to a protein carrier. Depending upon the number of serotypes, four types of polysaccharide protein conjugate vaccines; PCV-7, PCV-9, PCV-10 and PCV-13 are available. Currently, only10 and13-valent conjugate vaccines are available. Beside these, PPSV-23 vaccine is also available which is non-conjugate vaccine and is effective only in older children and adults. The earliest vaccine to be introduced was PCV-7 which covered $65-80 \%$ of serotypes associated with IPD among young children in western countries. PCV-9 had serotypes 1 and 5 in addition to those in PCV-7. PCV-13 contains serotypes $1,3,4,5,6 \mathrm{~A}, 6 \mathrm{~B}, 7 \mathrm{~F}, 9 \mathrm{~V}$, $14,18 \mathrm{C}, 19 \mathrm{~A}, 19 \mathrm{~F}$ and $23 \mathrm{~F}$.

Table No.-1: Types of vaccines available and its coherence with serotype diversity [16]

\begin{tabular}{|l|l|l|}
\hline $\begin{array}{r}\text { Type of } \\
\text { vaccine }\end{array}$ & \multicolumn{1}{|c|}{ Vaccine Serotypes } & $\begin{array}{c}\text { Common Serotypes in } \\
\text { India }\end{array}$ \\
\hline PCV 7 & $4,6 \mathrm{~B}, 9 \mathrm{~V}, 14,18 \mathrm{C}, 19 \mathrm{~F}, 23 \mathrm{~F}$ & $6 \mathrm{~A}, 6 \mathrm{~B}, 1,19 \mathrm{~A}, 19 \mathrm{~F}, 14,5,7$, \\
\hline $\mathrm{PCV} 9$ & $1,4,5,6 \mathrm{~B}, 9 \mathrm{~V}, 14,18 \mathrm{C}, 19 \mathrm{~F}, 23 \mathrm{~F}$ & \multirow{2}{*}{, 33, and 17 } \\
\cline { 1 - 2 } $\mathrm{PCV} 10$ & $\begin{array}{l}1,4,5,6 \mathrm{~B}, 7 \mathrm{~F}, 9 \mathrm{~V}, 14,18 \mathrm{C}, 19 \mathrm{~F}, \\
23 \mathrm{~F}\end{array}$ & \\
\hline PCV 13 & $\begin{array}{l}1,3,4,5,6 \mathrm{~A}, 6 \mathrm{~B}, 7 \mathrm{~F}, 9 \mathrm{~V}, 14,18 \mathrm{C}, \\
19 \mathrm{~A}, 19 \mathrm{~F}, 23 \mathrm{~F}\end{array}$ & \\
\hline
\end{tabular}

Immunogenicity, efficacy and safety of available vaccine: As per WHO PCV should be able to elicit IgG levels $>0.35 \mathrm{mcg} / \mathrm{ml}$ for all common serotypes collectively.
Amdekar YK et al in a randomized, activecontrolled, double-blind trial conducted at 12 sites in India observed that PCV-13had an acceptable safety profile in both infants and toddlers, comparable to that of PCV-7. Both PCV 10 and PCV13 have comparable immunogenicity interms of the proportion of subjects achieving serotype specific IgG antibody levels $\geq 0.35 \mu \mathrm{g} / \mathrm{ml}$ in the dosage schedules indicated by the manufacturer [17]. The Finnish trial hasshown $100 \%$ effectiveness of $3+1$ doses of PCV-10 and $92 \%$ for $2+1$ doses against IPD [18].

Vaccine cost and cost effectiveness: The current cost of the PCV vaccine is Rs. 1600/dose for PCV 10 vaccine and Rs. 3200/dose for the PCV 13 [16]. No study has been so far conducted in India regarding the cost-effectiveness of pneumococcal vaccines. Few European studies have shown favourable costeffectiveness of the vaccine.

However in a systematic review which included ten European studies regarding cost effectiveness of the new pneumococcal vaccines conducted by van de Vooren $\mathrm{K}$ et al suggested that though the studies supported the economic utility of the vaccine but as the studies included in the systematic review were mostly based on weak sources of data and had limited information on vaccine effectiveness, epidemiological and economic data.

It is also suggested that wing to the dynamic issue of serotype replacement, it should be monitored post-licensure and, as changes occur, vaccine effectiveness and cost-effectiveness analyses should be re-evaluated [19].

Preparedness of Health System: As per NFHS-4 data, immunisation coverage is around $62 \%$ in 2015-16 [2]. This underpins the fact that more efforts should be given in identifying and overcoming the barriers that impedes immunisation along with improving operational efficiency. According to Madhavi $Y$ et al, Rs.200 crores were spent every year for procurement of the 6 UIP vaccines but only half of over 26 million birth cohort per year were immunised. There was at least twofold enhancement of total cost of procurement by inclusion of hepatitis-Bin Universal Immunisation Programme. Estimated cost of including the pentavalent vaccine in the UIP (in place of DPT) as per the same study is around Rs. 1200 crores (Rs. 400 crores from the Indian Government and Rs. 800 crores from Global Alliance on Vaccine Initiative, GAVI, though for a limited period of time). 
Inclusion of more vaccines will lead to even more increase in the total Government procurement budget with additional costs of logistics, cold-chain, syringes, manpower related costs. Hence, the public health needs before introduction of any vaccine needs to be undisputedly established [20].

Vaccine Acceptability: There is paucity of primary data on demand, utilization, and the access to pneumococcal vaccination in India. In an exploratory study conducted by Zodpey et al, it was found that $67.7 \%$ of the paediatricians recommended pneumococcal vaccination to their clients. Majority (97.3\%) of the paediatricians reported that the main reason for a patient not following the advice for pneumococcal vaccination was the price of PCV.

Majority (74.1\%) of the paediatricians argued that PCV should be introduced in UIP to enhance equity in the access to PCV to ensure the access of PCV to impoverished population which is also at high risk of pneumonia. On the contrary, very few (17.7\%) of them were against its introduction owing to questions related to the efficacy and effectiveness of PCV in an Indian setting due to absence of any supporting evidence by clinical trial in India [21]. Similar findings were reported by Kahn GD et al [22].

A national survey conducted among the private sector paediatricians registered with the IAP has also reported that $85.6 \%$ of paediatricians administer PCV vaccine selectively or routinely [23]. Moreover, Farooque $\mathrm{H}$ et al estimated state-specific PCV coverage for the year 2012 had found that the overall PCV coverage in the private sector was around $0.33 \%$ (minimum $0.07 \%$ for Assamand maximum of $2.38 \%$ for Delhi).

Overall PCV coverage in other major cities were $13.31 \%$ for Mumbai,0.76\%forLucknow, $1.93 \%$ for Kolkata and $4.92 \%$ for Chennai. It opined to improve PCV coverage among population by both the demand side and the supply side to remove inequity in PCV access [24].

Need of Pneumococcal vaccine in UIP1: Pneumonia can be controlled by simple measures of prevention, protection and treatment like: Vaccination, Safe drinking water, good sanitation, and frequent hand washing with soap, improvement in indoor air quality, exclusive breastfeeding for first 6 months, good nutrition and recognizing danger signs of pneumonia and prompt initiation $f$ treatment [8].
Pneumococcal diseases are a common cause of morbidity and mortality worldwide, though rates of disease and death are higher in developing countries than in industrialized countries, with majority of deaths occurring in sub-Saharan Africa and Asia [9].

Hence pneumococcal vaccines can be an important public health tool to reduce the burden of pneumococcal diseases along with other interventions particularly in developing countries including India. The current cost of the vaccine justifies its inclusion in the National Immunization Program. But, introduction of pneumococcal vaccine in NIS raises certain issues like public health priority, assessment of candidate vaccine in the country and programmatic issues.

Additional factors like change in serotypes, efficacy, and cost effectiveness and challenges like probability of the non-vaccine serotypes replacing the vaccine types, change in pattern in antibiotic susceptibility in the non-vaccine serotypes and establishment of sentinel surveillance of pneumonia to observe the trends and to obtain a measure of effect of pneumococcal vaccine needs to be explored and considered [25].

\section{Conclusion}

Pneumococcal disease, including pneumococcal pneumonia and pneumococcal meningitis, can be treated with antibiotics, usually amoxicillin. However, in many countries strains of pneumococcus are becoming resistant to some of the commonly used antibiotics [8].

Pneumococcal infections which are resistant to these antibiotics require treatment using more expensive antibiotics which underpins the need of vaccination. Many countries have included PCV in the irregular immunisation programmes [26]. Also studies conducted regarding effectiveness of pneumococcal vaccines in developed countries how promising results.

These trends should not be used as a justification for their inclusion in the Indian Immunisation Programme as most of the available data on Pneumococcal diseases are on meningitis and from hospital based studies. Data regarding the burden of milder pneumococcal illnesses, such as sinusitis and otitis media are not available.

Also there are limited studies investigating the bacterial and viral etiology of Community Acquired 
Pneumonia; hence, more research is needed in this context. Introduction of pneumococcal vaccine in India should be based on substantial clinical and epidemiological evidence. In India the burden of pneumococcal diseases the greatest among the under privileged children.

How ever the high cost of PCVs and the limited coverage of the currently available vaccine are impediments. However a wide variation in prevalent serotypes demands prospective studies to formulate recommendations for specific pneumococcal vaccine introduction. Studies of short duration either overor under estimate the problem. Absence of data to show change in the serotype prevalence overtime poses questions regarding introduction of pneumococcal vaccine in the immunization schedule.

\section{Reference}

01. Govt Of India. Ministry of Health and Family Welfare. National Vaccine Policy, New Delhi. 2011 Apr;23.

Available from: [Article] [Crossref]

02. Govt Of India. Ministry of Health and Family Welfare. National Family Health survey (NFHS4), India Facts sheet. 2018. Available from: [Article] [Crossref]

03. Lahariya C. A brief history of vaccines \& vaccination in India. Indian J Med Res. 2014 Apr;139(4)491-511.

[Crossref]

04. Government of India and UNICEF. Ministry of Health and Family Welfare. Coverage evaluation survey- all India report. 2009.

Available from: [Article] [Crossref]

05. WHO and Maternal and Child Epidemiology Estimation Group (MCEE). Estimates of child cause of death,Acute respiratory infection 2015. Available from: [Article] [Crossref]

06. Yadav KK, Awasthi S. The current status of community acquired pneumonia management and prevention in children under 5 years of age in India- a review. Ther Adv Inf Dis. 2016 Jun;3(3-4)83-97.

doi: $10.1177 / 2049936116652326 \quad$ [Crossref]
07. Black RE, Cousens S, Johnson HL et al. Global, regional, and national causes of child mortality in 2008 -a systemic analysis. The Lancet. 2010 Jun;5;375(9730)1969-87.

doi: $10.1016 /$ S0140-6736(10)60549-1 [Crossref]

08. WHO. Pneumonia. Key facts. [Updated 2019 Aug 2; cited 2019 Nov 18].

Available from: [Article] [Crossref]

09. WHO. Immunization, Vaccines and Biologicals. Pneumococcal disease. 2014.

[Updated: 2014 Sep 29; cited 2019 Nov 18]. Available from: [Article] [Crossref]

10. Rudan I, Boschi-Pinto C, Biloglav Z, Mulholland $\mathrm{K}$, Campbell $\mathrm{H}$. Epidemiology and etiology of childhood pneumonia. Bull World Health Organ. 2008;86(5)408-416.

doi : $10.2471 /$ blt.07.048769 [Crossref]

11. Liu L, Johnson HL, Cousens S, Perin J, Scott S, Lawn JE, et al. Global, regional, and national causes of child mortality- An updated systematic analysis for 2010 with time trends since 2000 . Lancet. 2012 Jun;9;379;2151-2161.

doi: $10.1016 /$ S0140-6736(12)60560-1 [Crossref]

12. Jaiswal $N$, Singh $M$, Thumburu KK, Bharti $B$, Agarwal A, Kumar $A$ et al. Burden of Invasive Pneumococcal Disease in Children Aged 1 Month to 12 Years Living in South Asia- A Systematic Review. PLOS ONE. 2014 May5;9(5 )e96282.

doi: 10.1371/journal.pone.0096282 [Article] [Crossref]

13. Johnson $\mathrm{HL}$, Deloria $\mathrm{K} M$, Levine OS et al. Systematic evaluation of serotypes causing invasive pneumococcal disease among children under five- The pneumococcal global serotype project. PLoS Med. 2010;7(10)e1000348.

doi: 10.1371/journal.pmed.1000348 [Article] [Crossref]

14. Thomas K. Invasive Bacterial Infections Surveillance (IBIS) Group, International Clinical Epidemiology Network (INCLEN), Prospective multicentre hospital surveillance of Streptococcus pneumoniae disease in India. Lancet. 1999 Apr.

doi: 10:353(9160)1216-1221. [Article] [Crossref] 
15. Manoharan A. Surveillance of invasive disease caused by Streptococcus pneumoniae or Hemophilus influenzae or Neisseria meningitides in children ( $<5$ Years) in India, Alliance for Surveillance of Pneumococci (ASIP), Poster Discussion 2- Bacterial Infections 1, 13:30 to 15:30 Hours, May 30, 2013 at the 31st Annual Meeting of the European Society for Paediatric Infectious Diseases. Milan, Italy. May 28eJune 1, 2013.

[Crossref]

16. Malik A, Taneja DK. Conjugate Pneumococcal Vaccines- Need and Choice in India. Indian J Community Med. 2013 Oct-Dec;38(4)189-191. doi: $10.4103 / 0970-0218.120140$ [Crossref]

17. Amdekar $\mathrm{YK}$, et al. Immunogenicity and safety of a 13-valent pneumococcal conjugate vaccine in healthy infants and toddlers given with routine vaccines in India. Pediatr Infect Dis $\mathrm{J}$. 2013;32(5)509-16.

doi: 10.1097/INF.0b013e31827b478d [Crossref]

18. Palmu AA, Jokinen J, Borys D, Nieminen $H$, Ruokokoski E, Siira L, et al. Effectiveness of the ten-valent pneumococcal Haemophilus influenzae protein $D$ conjugate vaccine (PHiD-CV10) against invasive pneumococcal disease: A cluster randomised trial. Lancet. 2013;381(9862):214-22.

doi: $10.1016 /$ S0140-6736(12)61854-6 [Crossref]

19. Van de Vooren K, Duranti S, Curto A, Garattini $L$. Cost effectiveness of the new pneumococcal vaccines- a systematic review of European studies. Pharma co economics. 2014 Jan;32(1)29-45.

doi: $\quad 10.1007 / s 40273-013-0113-y \quad$ [Crossref]

20. Y Madhavi, Puliyel J M, Mathew J L, N Raghuram, Phadke A, Shiva M, S Srinivasan, et al. Evidence-based National Vaccine Policy. Indian J Med Res. 2010 May;131;617-628.

[Crossref]

21. Zodpey S, Farooqui H, Chokshi M, B R, Thacker $N$. Pediatricians' perspectives on pneumococcal conjugate vaccines- An exploratory study in the private sector. Ind Journal of public Health. 2015;59(3)225-229.

doi: $10.4103 / 0019-557 X .164667$ [Crossref]
22. Kahn GD, Thacker D, Nimbalkar S, Santosham M. High cost is the primary barrier reported by physicians who prescribe vaccines not included in India's Universal Immunization Program. J Trop Pediatr. 2014 Aug;60(4)287-91. doi: 10.1093 [Crossref]

23. Predictors of administration and attitudes about pneumococcal, Haemophilus influenzae type b and rotavirus vaccines among pediatricians in India- A national survey. J Vaccine. 2012 May 21;30(24)3541-5. doi: 10.

1016 [Crossref]

24. Farooqui H H, Zodpey S, Chokshi M, Thacker N. Estimates on State-Specific Pneumococcal Conjugate Vaccines (PCV) Coverage in the Private Sector in the Year 2012- Evidence from PCV Utilizatio Data. Indian J Public Health. 2016 Apr-Jun;60(2)145-9. doi: 10.4103/0019-557X.184572 [Crossref]

25. Kanungo R. Challenges to pneumococcal vaccine in India. Indian J Med Microbiol. 2013;31;1-2. doi: $10.4103 / 0255-0857.108701$ [Crossref] 